\section{In Pursuit of the Perfect Peach: Consumer-assisted Selection of Peach Fruit Traits}

\author{
Mercy A. Olmstead ${ }^{1}$ and Jessica L. Gilbert \\ Horticultural Sciences Department, University of Florida, Gainesville, FL \\ 32611
}

Thomas A. Colquhoun and David G. Clark
Environmental Horticulture Department and UF/IFAS Plant Innovation
Center, University of Florida, Gainesville, FL 32611

Robert Kluson

Sarasota County Extension, University of Florida, Sarasota, FL 34241

\author{
Howard R. Moskowitz \\ Moskowitz Jacobs, Inc., White Plains, NY
}

Additional index words. flavor, fruit texture, fruit quality, Prunus persica, consumer-assisted selection

\begin{abstract}
Despite production of the first domestically produced peach of the calendar year in the United States, the subtropical peach industry faces marketing challenges, particularly with small fruit size. Although important, size is only one aspect of fruit quality, and not inclusive of all possible fruit quality attributes. Thus, this research asked consumers to identify an "ideal" peach given a combination of possible peach fruit quality attributes to help determine their influence on consumer purchase. These attributes were verified with farmers' market intercept studies. The top attributes that fostered purchase likelihood included flavor, texture, size, and firmness. Psychophysics studies showed that consumers preferred peaches that were sweet, juicy, round, with freestone or semifreestone characteristics, whereas consumers were less likely to purchase peaches with mealy, dry, or meaty textures. Young consumers (ages 18-24) preferred crisp, firm peaches with good flavor, whereas older consumers (ages 51-65) preferred sweet, melting-texture peaches. Farmers' market intercept studies found consumers (ages 45-65) preferred meltingtexture peaches with good flavor that led to increased overall liking. In addition, in the farmers' market studies, aroma and flavor were important attributes and were highly correlated with overall liking. Objective measurements of total soluble solids (TSS) were not correlated with overall liking, indicating that although the nationwide experiment found consumers desired sweet peaches, other attributes may contribute more favorably to overall liking.
\end{abstract}

The Florida subtropical peach (Prunus persica L.) industry is expanding, with over 1200 acres in the state producing fruit predominantly for fresh market consumption. Growers are able to market the first domestically produced peach of the calendar year in late March and early April, resulting in estimated farm gate values of $\$ 1.50 / \mathrm{lb}$ compared with $\$ 0.80 / \mathrm{lb}$ in Georgia, whose production begins in early May (Morgan and Olmstead, 2013). Florida peaches are distributed predominantly to the eastern part of the United States, with national distribution

Received for publication 16 Apr. 2013. Accepted for publication 29 June 2013.

We thank Patricia Dewar and Tahj Hopkins for aiding with the IdeaMap ${ }^{\circledR}$ survey, and Dr. Tripti Vashisth and Sarasota County Extension Master Gardeners for helping to run the farmer's market surveys.

${ }^{1}$ Corresponding author. E-mail: mercy1@ufl.edu. likely in the next 5 years as acreage and volume increase (Harrison et al., 2008). Local and regional studies have shown favorable consumer acceptance of early season peaches (Brovelli et al., 1999; Williamson and Sargent, 1999). The stone fruit breeding program in Florida has focused on the release of nonmelting texture peaches for fresh consumption, which allows fruit to remain on the tree longer and develop improved aroma and flavor without sacrificing firmness (Do et al., 1969; Sherman et al., 1996; Sherman and Lyrene, 2003). Nonmelting texture peaches for the fresh market typically are clingstone or semifreestone with firm fruit flesh that does not breakdown as the fruit ripen (Van der Heyden et al., 1997), whereas melting-texture peaches often deteriorate in the shipping chain if harvested tree ripe (Brovelli et al., 1995; Lester et al., 1996). However, consumers can perceive this firmness as unripe fruit. Nonmelting texture, in addition to small fruit size in these early ripening varieties, presents significant marketing challenges to the growth of the subtropical peach industry.

Despite the growth in low chill, early season peach acreage from 234 acres in 2007 to over 1231 acres in 2012 (United States Department of Agriculture, 2012), overall peach and nectarine consumption has remained static or decreased (Grimm et al., 2010; United States Department of Agriculture, 2014). This may be caused by several factors such as poor fruit texture caused by flaws in the postharvest handling resulting in "wooly" or "mealy" fruit textures (Crisosto, 2002; Delgado et al., 2013; Diehl et al., 2013; Williamson and Sargent, 1999), small fruit size, low soluble solid content (SSC) (Kader, 1999), or significant reduction in skin color (e.g., blush) (Crisosto and Crisosto, 2005; Parker et al., 1991). Poor fruit quality as determined by small fruit size, low SSC, or reduced skin color may be driven by early harvests to minimize fruit damage in the shipping chain as fruit are shipped across the country to export markets overseas or for processing (Kader, 1999; Kader et al., 1982). The main drivers in initial peach purchases are appearance and aroma, and repeat purchases predominantly based on flavor and textural aspects (Baldwin, 2002; Bruhn, 1995; Bruhn et al., 1991; Delgado et al., 2013; Diehl et al., 2013). A minimum TSS of $10 \%$ has been proposed for maximum consumer acceptance (Kader, 1999); however, acidity and astringency also are important drivers in peach flavor (Predieri et al., 2006). Selection for flavor has not been a priority in perennial fruit breeding programs because of the importance of disease resistance, consistent fruit yield, and large fruit size (Gallardo et al., 2012; Laurens, 1999). In addition, fruit flavor can be affected by production practices (Olienyk et al., 1997) and postharvest supply chain conditions (Lurie and Crisosto, 2005). However, breeders, fruit growers, and market intermediaries are increasingly cognizant of the consumer demand for better fruit flavor (Colquhoun et al., 2012; Yue et al., 2013, 2014).

One important attribute that has been successfully used in fruit marketing is health benefits. For example, with blueberries, consumers were most interested in various aspects of blueberry flavor, but a significant segment of consumers was also very interested in the health benefits of consuming blueberries (Gilbert et al., 2014). Several studies have described the high antioxidant potential of peaches (Gil et al., 2002; Reig et al., 2013; Santos et al., 2013), and extracts of both peach and plum (Prunus salicina L.) may have cancersuppressive properties against certain breast cancer lines (Lea et al., 2008; Noratto et al., 2009). However, there have been few marketing efforts on behalf of these health compounds in peaches and other stone fruit.

Identification of visual and sensory attributes contributing to an "ideal" peach-eating experience is key to providing the necessary 
Gender
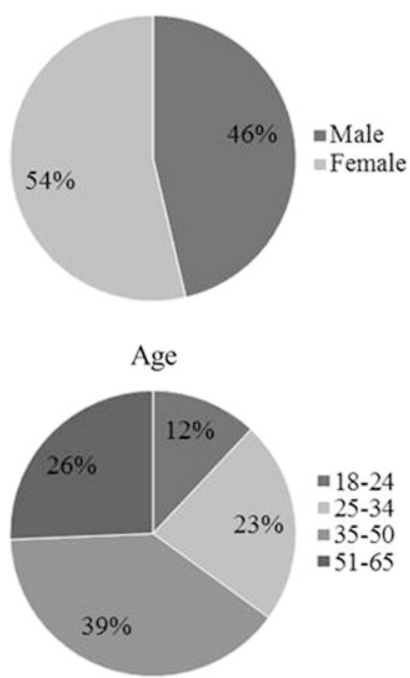

Race / Ethnicity
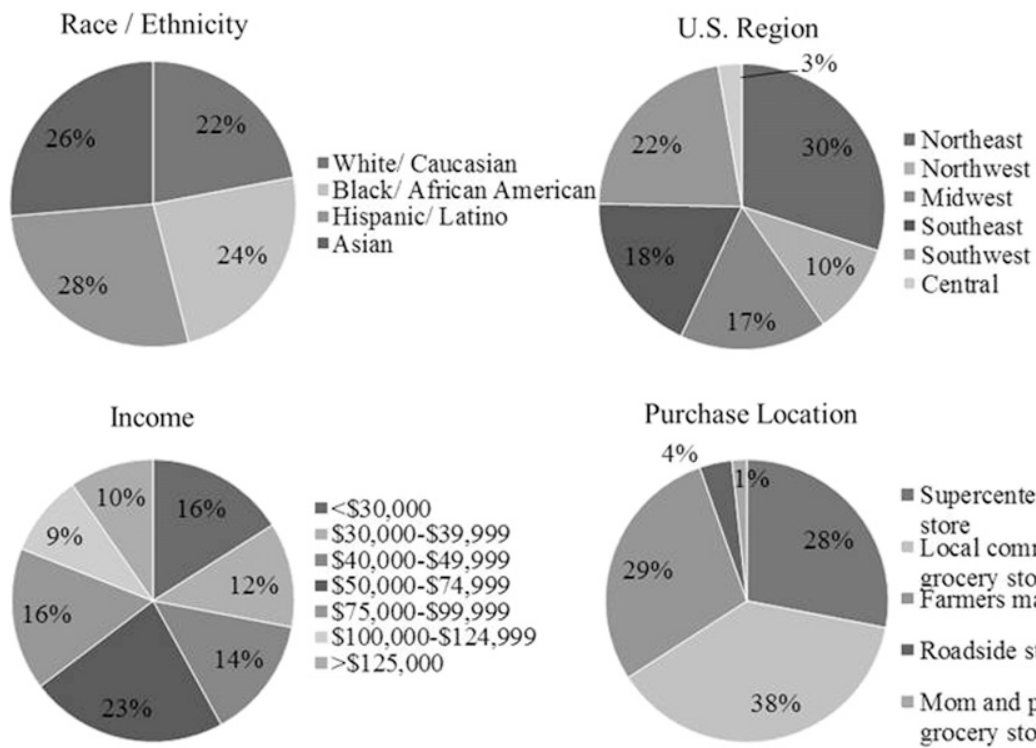

Fig. 1. Reported demographics of “The Ideal Peach” consumer perception survey $(N=300)$.

information that breeding programs, producers, and marketers need to drive increased consumption of peaches in the United States. Although individual fruit quality attributes have been tested in previous consumer preference studies, they have not been presented in combined formats. Thus, this study sought to identify the combination of attributes that would provide an ideal peach fruit quality profiles, which could be used by breeders, growers, and marketing intermediaries to promote peaches and encourage consumption of peaches in the United States.

\section{Materials and Methods}

Consumers were analyzed using rule developing experimentation (RDE) in which the potential consumer interest of products composed of new and different combinations of specific fruit quality attributes is assessed (Levin et al., 2012; Moskowitz and Gofman, 2007). RDE was implemented
Relationship
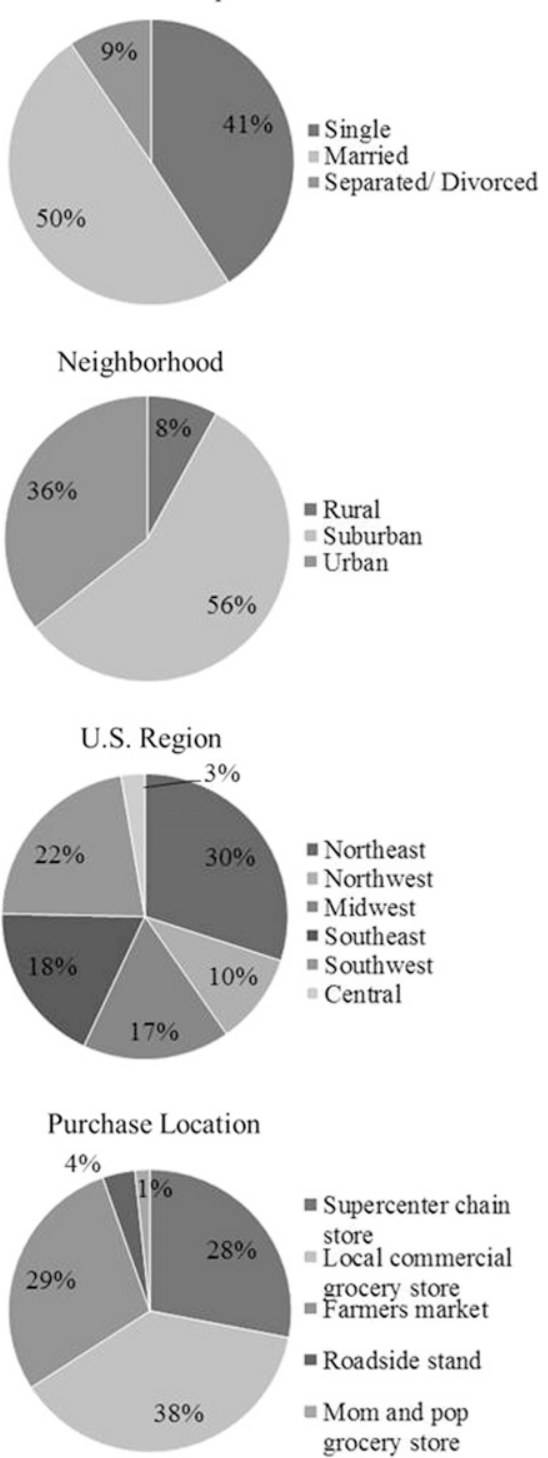

presented in Fig. 1. This study was exempt from institutional review board approval based on category 45 CFR 46.101 (b)(2)(i), as no personal identification of subjects was collected (United States Department of Health and Human Services, 2009).

In the IdeaMap ${ }^{\circledR}$ interface, consumers were asked about unique combinations of specific fruit quality attributes that may define a peach fruit to gauge interest levels. The main peach fruit characteristics chosen were based on previous research and included firmness, texture, size, color, flavor, and health and wellness (Brovelli et al., 1995, 1999; Karakurt et al., 2000; Rouse and Sherman, 2002). Each online respondent was presented with a welcome screen and sequentially asked to rate their likelihood of purchasing a peach defined by a combination of three to four different specific fruit quality attributes presented on the screen. Each of these attributes was from the six independent categories of peach quality attributes (Fig. 2; Table 1). For each screen presenting a combination of these fruit quality attributes, consumers indicated their purchase likelihood on a 9-point scale $(1=$ not at all likely, $9=$ very likely). Each of the 36 options (attributes; Table 1) appeared five times in 48 permutated combinations, and every study subject evaluated a unique set of 48 combinations with the same 36 attributes from the six categories.

Using regression analysis, independent variables (fruit quality attributes) were related to dependent variables (purchase likelihood/consumer interest). IdeaMap ${ }^{\circledR}$ technology uses modified conjoint analysis to determine the effect of a single independent variable presented in multiple combinations with other independent variables in a stacked six-level, six-variable matrix (Plackett and Burman, 1946). Ratings of product "concepts," the presented peach attribute combinations, were transformed to binary ratings of 0 (consumer disinterest, rating of 1 to 6 ) or 100 (consumer interest, rating of 7 to 9) for each panelist (Moskowitz, 2012; Moskowitz and Gofman, 2007; Moskowitz et al., 2006). This creates a matrix for each panelist of 48 rows (each attribute combination) by 38 columns (the presence/absence of an attribute in the rated combination, the panelist rating, and the transformed rating).

Regression modeling was used to determine which attributes drive liking/disliking as previously reported (Colquhoun et al., 2012; Gilbert et al., 2014), with an equation for the response matrix of each panelist of the form:

$$
\begin{aligned}
& \text { Rating }=\mathrm{k}_{0}+\mathrm{k}_{1}(\text { attribute A1 }) \\
& \quad+\mathrm{k}_{2}(\text { attribute A2 })+\ldots \\
& +\mathrm{k}_{36}(\text { attribute F6 })
\end{aligned}
$$
sought. After $\approx 150$ panelists of either gender completed the study, panelists of that gender were screened out. A total of 300 subjects completed the survey, with distribution for various demographic categories is where rating corresponds to the transformed value based on the panelist's response on the 9-point scale to a combination of three to four elements, $\mathrm{k}_{0}$ is the mean of all ratings of that panelist, and $\mathrm{k}_{1}-\mathrm{k}_{36}$ are coefficients 

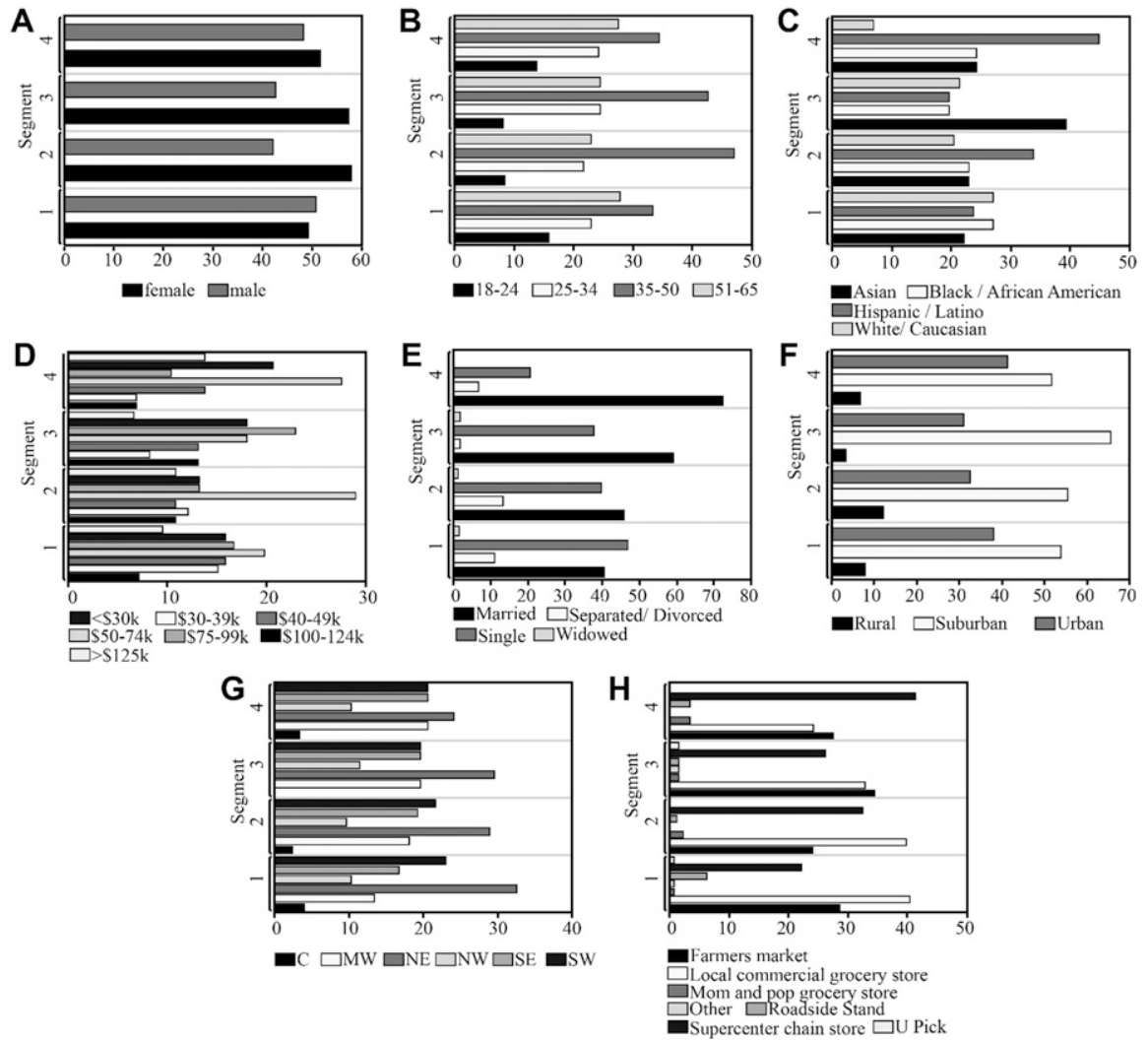

Fig. 2. An example of a combined peach attribute question presented to a survey participant in "The Ideal Fresh Peach" online survey. The participant responded to the question by indicating their likelihood of purchase for this specific combination of attributes on a 9-point scale, where 1 was not at all likely and 9 was very likely.

that correspond to the conditional probability a person will find a single element of the 36 presented interesting when the element is present in the combination (Moskowitz and Gofman, 2007). Interest values (InV) of peach fruit attributes 1-36, respectively, tested in this survey (Table 1). The InV of individual attributes describes the overall increase or decrease that a consumer would purchase that fruit relative to the baseline constant $\mathrm{k}_{0}$ (Moskowitz et al., 2006; Moskowitz and Gofman, 2007). A higher InV indicates greater likelihood of purchase generated by a particular attribute. The additive constant represents a baseline for comparison of the impact of an individual attribute on consumer preference. This constant also represents the general interest of respondents to the initial concept of the "ideal fresh peach" regardless of attribute influence. The InV of a certain attribute is shown as the difference in respect to the additive constant to show a particular increase or decrease in overall liking for that particular attribute (Gilbert et al., 2014; Moskowitz et al., 2006; Moskowitz and Gofman, 2007).

In this study, both a priori and post hoc analyses were used to look for market segmentation in the data. To see whether consumers clustered for similar peach attribute preferences, data were subjected to K-cluster analysis as previously described (Gilbert et al., 2014). K-cluster analysis was applied to the matrices of 36 columns (one column per attribute, value corresponding to its model coefficient/InV) and 300 rows (one row per respondent) in SYSTAT 13 (Systat Software, Chicago, IL).

Consumer preference study. To complement the IdeaMap ${ }^{\circledR}$ survey, consumer preference panels were conducted at four farmers' markets in the Sarasota-Bradenton, FL area in $2013(N=161)$ and $2014(N=184)$. In 2013, 'TropicBeauty' (melting texture) and 'UFSun' (nonmelting texture) peaches were harvested from the Plant Science Education and Research Center in Citra, FL. In 2014, 'TropicBeauty' fruit harvest was delayed, thus 'TropicBeauty' and 'UFSun' ripe fruit was sourced from King Family Farms (Bradenton, FL) for the farmer's market consumer preference panels. Tree-ripe fruit in both years were harvested into coolers containing ice and transported to refrigerated storage $\left(0{ }^{\circ} \mathrm{C}\right)$ until use. Fruit were allowed to ripen at room temperature $24 \mathrm{~h}$ before consumer acceptance studies were conducted. Flesh firmness (kgf) for every fruit that was served to consumers was measured by removing a small portion of the skin and a penetrometer reading was recorded (Model FT 10; Wagner Instruments, Greenwich, CT). This slice was subsequently removed from the fruit and used to extract juice for TSS measurement with a digital refractometer (PAL-1; Atago U.S.A.,
Inc., Bellevue, WA), whereas the remainder of the fruit was served to consumers.

Consumers were recruited to a booth at two local farmers' markets (Sarasota and Bradenton, FL) and were asked two demographic questions to identify their gender and age group (under 18, 18-29, 30-44, 45-65, over 65). Participants were then asked to rate visual appearance (skin color and shape) and aroma (orthonasally) of two peach samples in a questionnaire. Two slices each of the two peach cultivars were then given to subjects and they were asked to consume the peach slices and individually (by sample) rate the texture, firmness, flavor, and overall liking. Bottled water was given to each subject and used to rinse their palates between samples. Subjects rated each attribute using a 9-point hedonic scale $(1=$ dislike extremely, $9=$ like extremely).

Statistical analyses were completed using paired $t$ tests for each attribute, using JMP Pro (v. 11.0; SAS Institute, Cary, NC), and multivariate correlation analysis was used to determine the Pearson's correlation coefficient $(R)$ value of a particular attribute on another. This study was exempt from institutional review board based on category 45 CFR 46.101(b)(6) due to fruit not containing additives (United States Department of Health and Human Services, 2009).

\section{Results}

Consumer peach fruit quality interest study. The demographics of IdeaMap ${ }^{\circledR}$ participants approximated our desired gender distribution with $46 \%$ male and 54\% female, fairly even distribution among races and slightly higher percentage of 35- to 50-year olds compared with the other age categories (Fig. 1). Survey participants rated 48 sets of three to four individual attributes for likelihood of purchase (Table 1). The baseline constant for this study was 41 , which represented the average response of all panelists to all attributes. The highest ranking attributes that increased purchase likelihood belonged to the categories of flavor, texture, size, and firmness (Table 2). The top attribute was "so sweet ... no sugar needed" ( InV = 12), followed by "full of juice," "plump and round," "pit comes easily free from the peach flesh," and "sweet rich flavor with mildly tart overtones." The perception of "mealy ... pasty and dry" peaches was the strongest detractor of peach purchase likelihood $(\mathrm{InV}=-18)$. Other attributes with very negative $(\mathrm{InV}<-8)$ impacts on purchase decision were peaches that were "meaty ... not juicy," "flat, shaped like a donut," and "elongated shape (beaked) with a characteristic suture."

Women more willing to purchase peaches compared with men (constant $=50$ and 30 , respectively), and this sentiment was reflected in Fresh Trends data (Fresh Trends, 2011, 2012) (Table 3). Men and women did not segregate for purchase detractors, but men responded more favorably to the description "plump, round, sweet peaches," 
Table 1. Experimental design of categories (A-F) and individual attributes (1-6) of each category for the 2014 "The Ideal Fresh Peach" consumer perception study. ${ }^{z}$

The ideal fresh peach

\begin{tabular}{|c|c|}
\hline \multicolumn{2}{|c|}{ Category A: peach firmness } \\
\hline A1 & Bite into peach ... and hear a loud crunch \\
\hline $\mathrm{A} 2$ & Melts in the mouth when you bite into the peach \\
\hline A3 & Thin skin that melts away \\
\hline A4 & Tough chewy skin \\
\hline A5 & Peach clings to the pit \\
\hline A6 & Pit easily comes free from the peach flesh \\
\hline \multicolumn{2}{|c|}{ Category B: peach texture } \\
\hline B1 & Smooth skin with very little fuzz \\
\hline B2 & Typical fuzzy peach skin \\
\hline B3 & Full of juice \\
\hline B4 & Meaty ... not juicy \\
\hline B5 & Mealy ... pasty and dry \\
\hline B6 & Crisp and firm \\
\hline \multicolumn{2}{|c|}{ Category $\mathrm{C}$ : peach size } \\
\hline $\mathrm{C} 1$ & Plump and round \\
\hline $\mathrm{C} 2$ & Elongated shape (beaked) with characteristic suture \\
\hline C3 & As big as a small softball \\
\hline $\mathrm{C} 4$ & Small, bite-sized peaches \\
\hline $\mathrm{C} 5$ & Medium size, like a baseball \\
\hline C6 & Flat, shaped like a donut \\
\hline \multicolumn{2}{|c|}{ Category D: peach color } \\
\hline D1 & All-over blush, almost solid red in skin color \\
\hline D2 & Mainly yellow skin color, with a slight blush \\
\hline D3 & White flesh color \\
\hline D4 & Bright yellow flesh color \\
\hline D5 & Yellow flesh color with red flesh near the pit \\
\hline D6 & Red skin color that bleeds into the flesh \\
\hline \multicolumn{2}{|c|}{ Category E: peach flavor } \\
\hline E1 & Mild flavor ... but compliments well \\
\hline E2 & Bold and intense peach flavor \\
\hline E3 & So sweet ... no sugar needed \\
\hline E4 & Tart peach that wakes the taste buds \\
\hline E5 & Soft peach flavor, but are much more floral tasting \\
\hline E6 & Sweet rich flavor with mildly tart overtones \\
\hline \multicolumn{2}{|c|}{ Category F: health and wellness } \\
\hline $\mathrm{F} 1$ & Full of antioxidants \\
\hline $\mathrm{F} 2$ & No fat ... no cholesterol \\
\hline F3 & High in vitamin $\mathrm{C}$ \\
\hline F4 & A rich source of dietary fiber \\
\hline F5 & Organic peaches \\
\hline F6 & A low-carb source of nutrients \\
\hline
\end{tabular}

${ }^{\mathrm{z} E a c h}$ category represents an attribute of peaches such as peach firmness, peach texture, peach size, peach color, peach flavor, and health and wellness. Within each category are six descriptive attributes related to the category resulting in a total of 36 individual attributes.

whereas women responded most favorably to "sweet, juicy peaches," indicating that men were interested in visual attributes of peach fruit compared with women.

In this study, the age group that was most likely to purchase peaches (as determined by constant values) were panelists between 18 and 24 years, whereas those between 51 and 65 years were least likely to purchase peaches (constants $=54$ and 26, respectively) (Table 3 ). In examining each age group, many of the top and bottom attributes from the study as a whole were similar. However, the 18 to 24 age group was unique in that they responded favorably to the description of crisp, firm peaches, organically produced, and unfavorably to bright yellow, mildly flavored fruit. The 51-65 age group was very motivated to purchase peaches described as melting $(\operatorname{InV}=14)$ with sweet flavor $(\operatorname{InV}=19)$.

When analyzed by ethnicity, Asian panelists were most interested in peaches (constant $=53)$, followed by Black/African American (48), Hispanic/Latino (45), with "no fat ... no cholesterol" and "bite into peach ... and hear a loud crunch" resulted in strongly negative effects on purchase likelihood in this group. In both suburban and urban groups, peaches with sweet flavors increased the likelihood of purchase (Table 3). There were also differences in regional areas of the United States with panelists in the northwest most receptive to peaches, whereas panelists in the central United States least receptive (constant $=61$ and 30 , respectively) (Table 3 ). Panelists in the northwest were interested in sweet peaches with rich flavor, whereas those in the central United States were interested in peaches as "a low carb source of nutrients." Southwesterners were most interested in peaches with melting texture, whereas those in southeastern United States preferred sweet peaches with "thin skin that melts away," freestone in nature and full of juice. Ironically, there was a fairly low interest level in peaches for consumers in the southeastern United States (Table 3), a region that is known to produce a majority of the peach volume in the eastern United States.

Point of purchase has an impact on ideal peach attributes. Panelists that purchased peaches from neighborhood grocery stores had the highest interest, compared with local commercial grocery store shoppers, who had the lowest interest (constant $=63$ vs. 29) (Table 3). Local commercial grocery store shoppers made up the largest group $(n=112)$, yet were not interested in flavor attributes, contrary to the study as a whole. Panelists who purchased their peaches from roadside stands were most receptive to peaches with high amounts of blush and smaller diameter, but did not like peaches with little or no fuzz on the peach skin (Table 3).

To examine whether the data segmented into groups of clusters and identify unique groups of consumers, K-cluster analysis was used. Segments of two or three were not informative and produced similar results for top and bottom attributes. However, on segmentation into four clusters, distinct groups of consumers began to emerge with similar distributions of gender, age groups, and U.S. regions of residence $(K=4)$ (Fig. 3; Table 4). The largest segment (Segment 1, $n=126$ ) had the lowest overall interest in peaches but was most interested in purchasing sweet, freestone peaches with thin skin. The second segment of panelists $(n=83)$ had very negative reactions to crisp peaches with tough chewy skin and dry texture, but had very high responses to attributes of peach flavor, including elevated sweetness. The third segment $(n=61)$ was most interested in descriptors of size and shape; however, they responded negatively to peach skin and flesh color attributes, particularly to peaches with white flesh. A notable characteristic of this segment is that there were more Asians than other ethnicities, in addition to being from suburban neighborhoods in the northeastern United States (Fig. 3). The final segment $(n=29)$ had the highest baseline 
Table 2. Interest values (InV) of each attribute tested in "The Ideal Fresh Peach" consumer preference survey, ordered from highest to lowest. InV represent an increase or decrease relative to the baseline constant value (the percentage of subjects that would respond favorably to "The Ideal Peach" even if no attributes were presented).

\begin{tabular}{|c|c|c|}
\hline \multicolumn{3}{|c|}{ The ideal fresh peach } \\
\hline & Base Size & 300 \\
\hline & Constant & 41 \\
\hline & Attribute & $\operatorname{InV}$ \\
\hline$\overline{\mathrm{E} 3}$ & So sweet $\ldots$ no sugar needed & 12 \\
\hline B3 & Full of juice & 10 \\
\hline $\mathrm{C} 1$ & Plump and round & 8 \\
\hline A6 & Pit easily comes free from the peach flesh & 8 \\
\hline E6 & Sweet rich flavor with mildly tart overtones & 8 \\
\hline A2 & Melts in the mouth when you bite into the peach & 5 \\
\hline A3 & Thin skin that melts away & 4 \\
\hline F3 & High in vitamin $\mathrm{C}$ & 4 \\
\hline $\mathrm{C} 3$ & As big as a small softball & 4 \\
\hline $\mathrm{E} 2$ & Bold and intense peach flavor & 3 \\
\hline D6 & Red skin color that bleeds into the flesh & 2 \\
\hline B1 & Smooth skin with very little fuzz & 2 \\
\hline D1 & All-over blush, almost solid red in skin color & 2 \\
\hline F4 & A rich source of dietary fiber & 2 \\
\hline B6 & Crisp and firm & 2 \\
\hline F5 & Organic peaches & 1 \\
\hline D5 & Yellow flesh color with red flesh near the pit & 1 \\
\hline B2 & Typical fuzzy peach skin & 1 \\
\hline $\mathrm{C} 5$ & Medium size, like a baseball & 1 \\
\hline D4 & Bright yellow flesh color & 1 \\
\hline $\mathrm{F} 1$ & Full of antioxidants & 1 \\
\hline F6 & A low-carb source of nutrients & 1 \\
\hline D2 & Mainly yellow skin color, with a slight blush & 0 \\
\hline $\mathrm{F} 2$ & No fat ... no cholesterol & -1 \\
\hline $\mathrm{E} 4$ & Tart peach that wakes the taste buds & -1 \\
\hline D3 & White flesh color & -2 \\
\hline A1 & Bite into peach $\ldots$ and hear a loud crunch & -2 \\
\hline E5 & Soft peach flavor, but are much more floral tasting & -2 \\
\hline A5 & Peach clings to the pit & -3 \\
\hline E1 & Mild flavor ... but compliments well & -3 \\
\hline $\mathrm{C} 4$ & Small, bite-sized peaches & -3 \\
\hline A4 & Tough chewy skin & -7 \\
\hline $\mathrm{C} 2$ & Elongated shape (beaked) with characteristic suture & -8 \\
\hline C6 & Flat, shaped like a donut & -8 \\
\hline B4 & Meaty, not juicy & -11 \\
\hline B5 & Mealy ... pasty, and dry & -18 \\
\hline
\end{tabular}

interest in peaches, but was uninterested in peach flavor. Instead, they were more likely to purchase peaches described as being smooth, juicy, and bright yellow in flesh. This segment was made up of a large proportion of Hispanics compared with other ethnicities, with purchases made in suburban supermarket chain stores.

Consumer preference study. In the farmers' market survey (Sarasota, FL), fewer questions were asked of the participants compared with the national online survey; however, they were asked to evaluate the sensory aspects of whole fruit and peach slices, which was not possible with the online survey. Each of the two peach samples, 'UFSun' and 'TropicBeauty', which were given to participants in the farmers' market studies embodied attributes that were included in the Ideamap ${ }^{\circledR}$ survey, such as those for melting/nonmelting texture, mild or bold peach flavors, and pit characteristics such as freestone or clingstone. 'UFSun' is a round, moderately blushed peach with nonmelting texture, yellow flesh, and a clingstone pit (Fig. 4A). 'TropicBeauty' is also a round, moderately blushed peach, but with melting texture, yellow flesh, and a semifreestone pit (Fig. 4B).
Women were the predominant subjects intercepted in the farmers' market studies in both years while the predominant age group was 45-65 years old (Fig. 5). The location of the farmer's market in a coastal Florida community with a high proportion of retirees, may have affected age group distribution. In 2013, subjects preferred the aroma, texture, firmness, and flavor of 'TropicBeauty' compared with 'UFSun' $(P<0.05$; Table 5), which resulted in higher overall liking scores for 'TropicBeauty'. In 2014, subjects again preferred 'TropicBeauty' over 'UFSun', as indicated by higher ratings for texture, flavor, and overall liking $(P<0.05$; Table 5$)$.

In both years, significant strong positive correlations $(R>0.60)$ were found between color and shape, flavor and overall liking, texture and overall liking, flavor and texture, and firmness and overall liking (Table 6). The most consistent correlations were those with color, shape, texture, firmness, flavor, and overall liking in both years. There was a fairly weak correlation between TSS and all attributes, whereas objective measurements of firmness (kgf) were weakly negatively correlated with most attributes (Table 6). As expected, ratings of firmness and texture in both years were strongly correlated.

In 2013, TSS did not significantly differ in either peach variety, whereas in 2014 'TropicBeauty' had greater TSS than in 'UFSun' (Table 5). However, this objective measurement of soluble solids was not correlated with overall liking. Both peach varieties tested had typical acidity levels, and were not subacid varieties (Rouse and Sherman, 2002; Rouse et al., 2004) (Fig. 4).

\section{Discussion}

Peach fruit vary in size, shape, skin/flesh color, aroma compounds and phytochemical attributes, and appeal to multiple senses, including visual, olfactory, and tactile attributes that are important in peach purchases (Bruhn, 1995; Bruhn et al., 1991). The combination of these fruit quality attributes drives not only initial purchases, but return purchases, driving consumer demand. In this study, the "ideal peach" depended on different combinations of these fruit quality attributes that allowed the panelists to respond to a potential peach purchase situation and helped reduce cognitive bias directed at individual attributes (DellaVigna, 2009; Price and Riis, 2012; Redelmeier and Dickinson, 2011).

Peaches that were "so sweet ... no sugar needed" were most likely to increase consumer purchase likelihood, similar to those studies conducted in reference to strawberries and blueberries (Colquhoun et al., 2012; Gilbert et al., 2014). In peach, a minimum of $10 \%$ TSS has been recommended for consumer acceptance, and fruit with less than $10 \%$ TSS were rated as having low fruit quality (Crisosto and Crisosto, 2005; Robertson et al., 1989). However, in the farmers' market validation study, TSS (\%) was not related to overall liking (Table 6). Thus, although consumers perceive high sugar content as related to flavor and liking, sugar content alone is not the likely driver of overall liking in fresh peaches. In one study, a significant relationship was not found between individual sugars in peach and sensory panel ratings of sweetness, yet there was a significant relationship between the sugar to acid ratio and perceived sweetness (Colaric et al., 2005). Acidity and astringency were found to have strong positive relationships with liking of peach samples $\left(R^{2}\right.$ $=0.60$ and 0.65 , respectively) (Predieri et al., 2006). However, the relationship between liking and sweetness was weak $\left(R^{2}=0.21\right)$ and the authors hypothesized that the relationship may not even be linear. In 'Harvester' peaches, as sucrose and volatiles increased and acid concentration decreased, the sensory panel acceptability increased; however, no statistical tests of the data were done to show significance of this relationship (Meredith et al., 1989). High TA has been correlated to lower consumer acceptance of peach fruit (Crisosto et al., 2006); however, a combination of acidity, aroma, and flavor components are optimal when fruit are physiologically ripe 


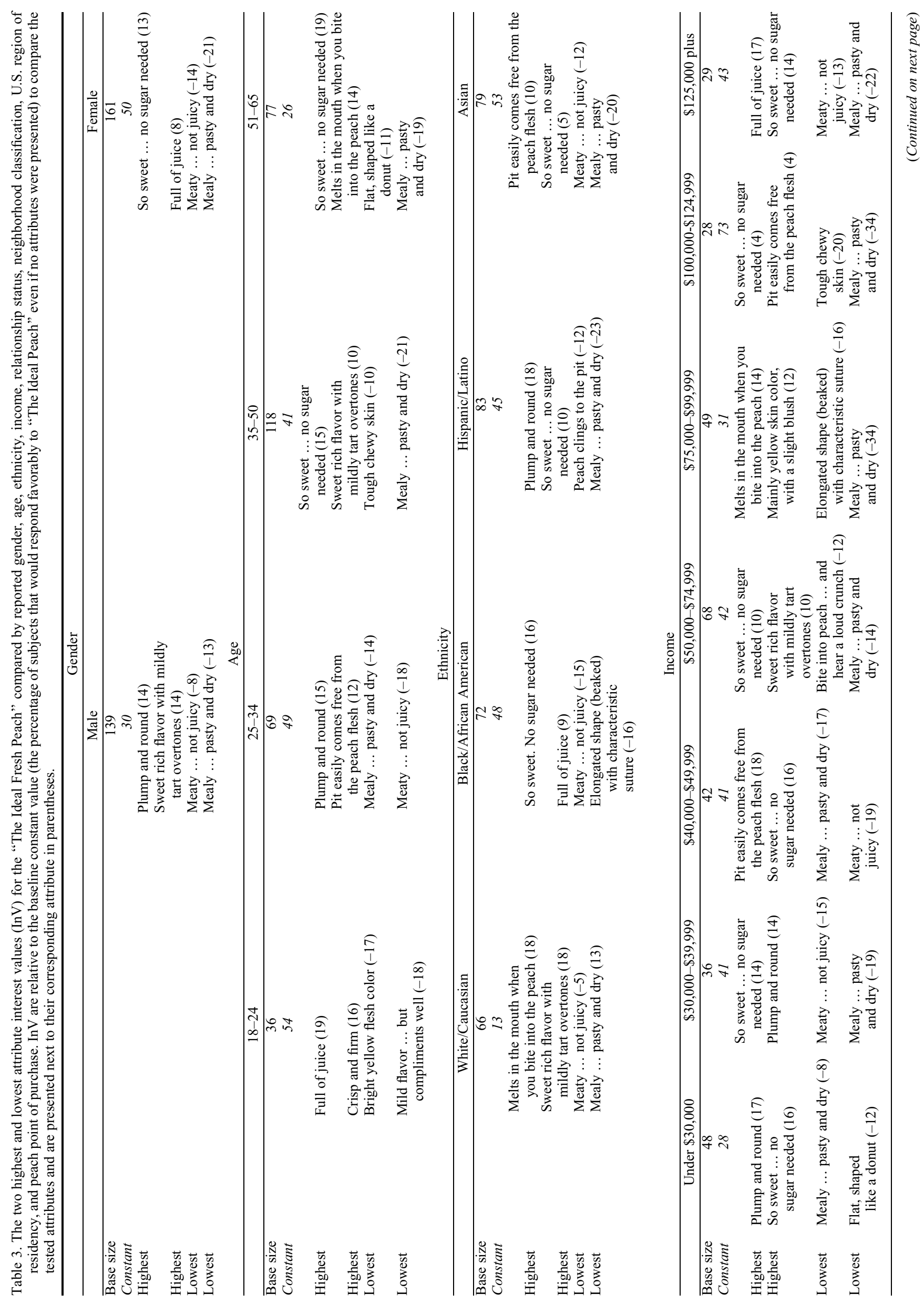




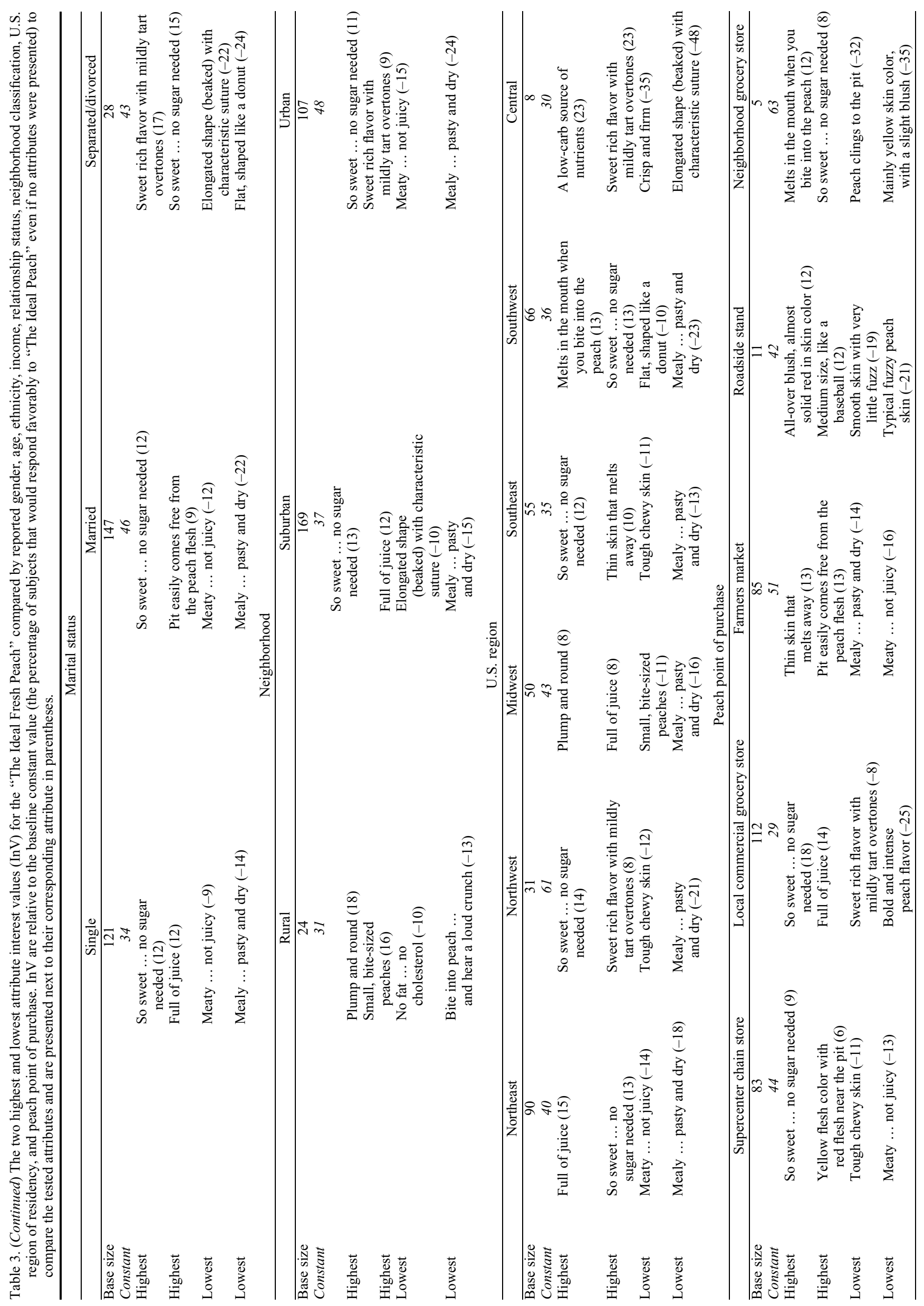


Pit easily comes free from the peach flesh

Medium size, like a baseball

So sweet...no sugar needed

A low-carb source of nutrients

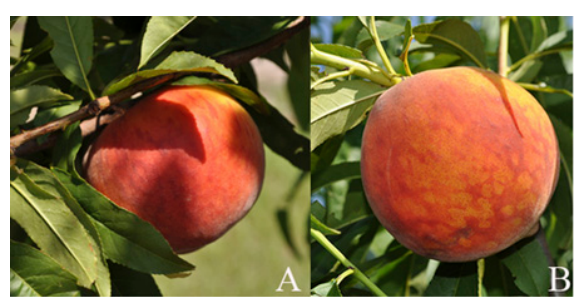

Fig. 4. 'UFSun' fruit (A) and 'TropicBeauty' fruit (B) used in farmers' market intercept surveys showing shape and color attributes.

Consumers in all segments and categories had a very negative response to the description of mealy, pasty, dry peaches, which mirrored previous studies in blueberry and apple (Gilbert et al., 2014; Jaeger et al., 1998). In peaches, this mealy texture is most often caused by internal tissue breakdown due to chilling injury (CI) (Lurie and Crisosto, 2005), and can significantly lower the consumer acceptability of fruit with above-average peach flavor metrics (Crisosto, 2002). In peach, mealy texture is partly determined by texture type (melting) and genetic tests have been developed to screen for susceptible varieties in breeding programs (Martínez-García et al., 2012).

Given this strong aversion to mealy texture, we were interested to test whether the difference between melting texture and nonmelting texture resulted in changes to overall liking. In a previous study, panelists scored peaches higher that were firmer; however, the four peach varieties tested were melting texture and is therefore not informative in comparing nonmelting varieties (Robertson et al., 1989). Sensory differences can be detected between melting and nonmelting peach texture, but preference for one texture type over another has not been measured (Brovelli et al., 1999). Our online study and the farmers' market survey suggests that most consumers prefer melting peaches, but small segments of the population are receptive to crisp and firm peaches (18-24 age group). This could indicate a shift in preferences for nonmelting peach texture or slightly underripe fruit as this younger generation become the major produce buyers in their household.

Despite inquiries about the interest in the health aspects of peaches, this category was not of major interest for any group of survey participants. Although peaches have been shown to have antagonistic properties for different cancer types, consumers may not be aware of the health benefits of peaches. For marketing intermediaries, this is an educational opportunity for those striving to increase peach consumption in the United States.

Age had a particular influence on those purchasing fresh peaches, with those between 51 and 68 years of age were the least interested, whereas those with the greatest interest were aged 18-24 years. Older consumers may have experienced repeated purchases of poor peach fruit quality that their interests have shifted to other fruit
(Delgado et al., 2013; Do et al., 1969; Kao et al., 2012; Schwieterman et al., 2014). In this study, TA of fruit served to farmer's market survey participants was not examined as there are few inexpensive in-field instruments for TA. 
Table 5. Consumer acceptance of skin color, fruit shape, fruit aroma, fruit texture, fruit firmness, flavor, and overall liking for two peach varieties, 'UFSun' and 'TropicBeauty' during farmers' market intercept studies in 2013. Objective measurements of ${ }^{\circ}$ Brix and firmness (kgf) were correlated with individual surveys.

\begin{tabular}{|c|c|c|c|c|}
\hline \multirow[b]{2}{*}{$\mathrm{Yr}$} & \multicolumn{4}{|c|}{ Variety } \\
\hline & Sensory measure & UFSun & TropicBeauty & $P$ value \\
\hline \multirow[t]{9}{*}{$\overline{2013}$} & Skin color & 7.5 & 7.6 & NS \\
\hline & Fruit shape & 7.6 & 7.6 & NS \\
\hline & Fruit aroma & 6.3 & 7.6 & $<0.001$ \\
\hline & Fruit texture & 6.7 & 7.3 & 0.02 \\
\hline & Fruit firmness & 6.6 & 7.4 & $<0.001$ \\
\hline & Flavor & 6.7 & 7.4 & 0.04 \\
\hline & Overall liking & 6.6 & 7.3 & 0.03 \\
\hline & Soluble solids (\%TSS) & 9.3 & 9.3 & NS \\
\hline & Firmness (kgf) & 1.1 & 0.7 & 0.002 \\
\hline \multirow[t]{9}{*}{2014} & Skin color & 7.5 & 7.7 & NS \\
\hline & Fruit shape & 7.6 & 7.4 & 0.04 \\
\hline & Fruit aroma & 7.5 & 7.6 & NS \\
\hline & Fruit texture & 7.0 & 7.4 & NS \\
\hline & Fruit firmness & 7.0 & 7.2 & NS \\
\hline & Flavor & 6.9 & 7.4 & 0.009 \\
\hline & Overall liking & 6.9 & 7.4 & 0.009 \\
\hline & Soluble solids (\%TSS) & 10.4 & 11.2 & $<0.001$ \\
\hline & Firmness (kgf) & 1.1 & 0.1 & $<0.001$ \\
\hline
\end{tabular}

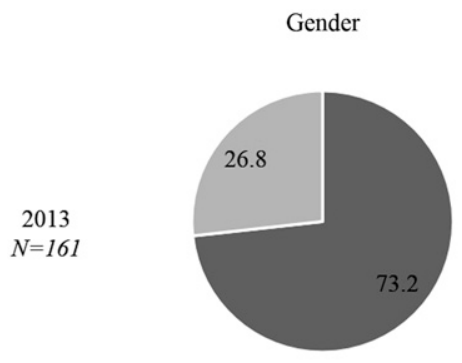

- Female $=$ Male

Gender

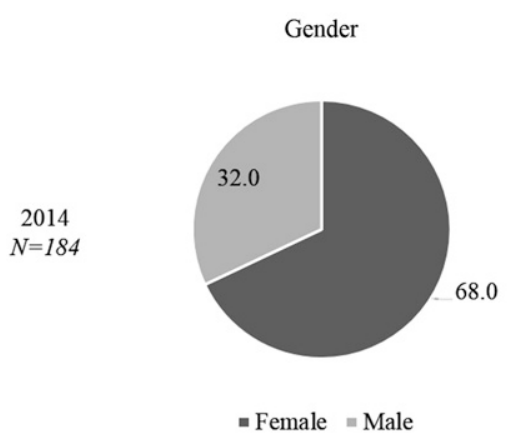

- Female $=$ Male

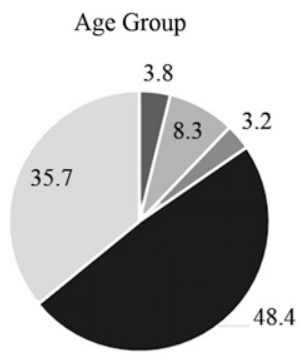

- Under $18=18-29=30-44=45-65=$ Over 65

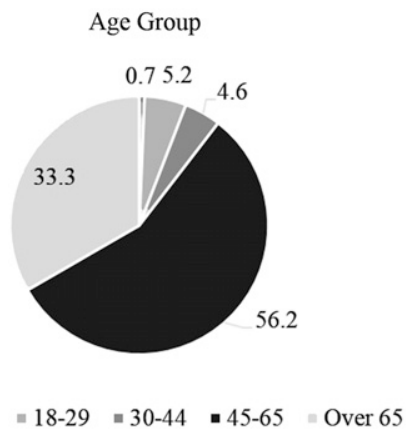

Fig. 5. Reported demographics of the 2013-14 farmers' market intercept surveys $(N=345)$.

categories; however, this was not examined in this study. In regard to the younger generation, their interest is perhaps indicative of the successful fruit purchasing messages to increase fruit consumption. Repeated follow-up surveys of this group as they age may show a sustained interest in peach purchases.

Consumers that most often purchased from local commercial grocery stores or supercenter chain stores did not respond favorably to flavor attributes, possibly indicating that their past peach purchases have not consistently provided good fruit flavor. Postharvest efforts on peach/stone fruit ripening over several decades have shown harvesting of fruit that is physiologically ripe must be properly handled to deliver an acceptable product (Crisosto, 2006). Recent efforts from major supermarket chains to promote "local" produce with better flavor is one way marketers can increase peach purchases in urban markets, provided fruit have excellent flavor.

The segmentation of panelists by their responses revealed four unique groups of consumers who value different peach attributes (Table 4). The largest group (Segment 1), "Sweet/Freestone," made the majority of their purchases from roadside stands and was more receptive to small-sized fruit that were freestone. For growers, selling produce via road stand markets is an important avenue for sales of fruit that do not meet minimum commercial standards, which are often based on peach fruit size. The second segment, the "Peachy Flavor" cluster, was made up by more suburban subjects than any other segment. Consumers in this segment wanted sweet peaches with bold or rich peach flavors, and were largely Hispanic consumers that purchased peaches in either their local commercial grocery store or a supercenter chain store. As this segment of the U.S. population increases, marketing messages should target this sector of consumers in both local and superchain grocery stores. Segment 3, which "Sees Size, Not Color," was largely composed of those from Asian descent. Thus, visual appearances and large fruit size may trigger an initial purchase, but a range of textures will drive repeat purchases based on the responses of this segment. Segment 4 may have most exposure or increased preference for "Canned Peaches" or "Nectarines" based on their affinity for smooth, juicy, bright yellow peaches. These panelists were far more likely to be married than single, and had the largest proportion of Hispanics compared with other segments. In fact, there was not one combination of peach attributes that was ideal for all segments, but four different combinations of attributes that targeted a majority of the consumers in this study. Differentiation in the peach market based on these segments may draw in new consumers with targeted marketing efforts, and focus on the most important traits for each segment may reinforce repeat purchases.

Overall, we found that consumers in both the online and the farmer's market studies preferred peaches that were sweet, had melting texture and good flavor. In breeding programs with a strong focus on nonmelting textures, this information indicates that having a diversified portfolio of melting, slow-melting, and nonmelting texture selections will target a broader consumer base. The ideal peach shape was one that was "plump and round" as shown by the preference of farmers' market survey participants to 'UFSun', a characteristically round fruit compared with 'TropicBeauty'. Fruit with elongated shapes and prominent sutures are often not selected in breeding programs in favor of uniformly round peach fruit. There were segments of consumers that could be targeted with peaches that have unique attributes such as crisp, firm texture (e.g., nonmelting texture), but additional marketing and educational efforts are needed for unique fruit shapes such as peen-to or donutshaped peaches to increase consumer acceptance. Future research will address specific interests in health attributes, peach fruit consumption by category (i.e., fresh consumption, processed in yogurt, smoothies, etc., or desserts), and detailed texture descriptions to examine the relationship between consumer acceptance and melting/nonmelting texture peaches. 
Table 6. Pearson correlation coefficient $(R)$ values between sensory and quantitative scores for all peach atributes measured among during farmers' market surveys [Sarasota, FL, in $2013(N=161)$ and $2014(N=184)$ ].

\begin{tabular}{|c|c|c|c|c|c|c|c|c|c|c|}
\hline Yr & Category/measurement & Color & Shape & Aroma & Texture & Firmness & Flavor & Overall liking & ${ }^{\circ}$ Brix & Firmness (kgf) \\
\hline \multirow[t]{6}{*}{$\overline{2013}$} & Color & 1.00 & $0.65^{* 2}$ & $0.39^{*}$ & $0.39^{*}$ & $0.36^{*}$ & $0.34 *$ & $0.39^{*}$ & $0.15^{*}$ & -0.03 \\
\hline & Aroma & & & 1.00 & $0.38^{*}$ & $0.37 *$ & $0.38^{*}$ & $0.39 *$ & $0.14^{*}$ & -0.15 \\
\hline & Texture & & & & 1.00 & 0.76 * & $0.72 *$ & $0.79 *$ & $0.16^{*}$ & -0.05 \\
\hline & Flavor & & & & & & 1.00 & $0.93 *$ & $0.23 *$ & -0.03 \\
\hline & Overall Liking & & & & & & & 1.00 & $0.23 *$ & 0.01 \\
\hline & ${ }^{\circ}$ Brix & & & & & & & & 1.00 & 0.00 \\
\hline \multirow{7}{*}{2014} & Shape & & 1.00 & $0.39 *$ & $0.23 *$ & $0.19^{*}$ & $0.22 *$ & $0.21 *$ & -0.02 & 0.03 \\
\hline & Aroma & & & 1.00 & $0.22 *$ & $0.19 *$ & $0.33^{*}$ & $0.32 *$ & 0.01 & -0.07 \\
\hline & Texture & & & & 1.00 & 0.80 * & 0.70 * & $0.74 *$ & 0.11 & $-0.15^{*}$ \\
\hline & Firmness & & & & & 1.00 & $0.67^{*}$ & $0.69^{*}$ & 0.09 & -0.09 \\
\hline & Flavor & & & & & & 1.00 & $0.86^{*}$ & 0.10 & $-0.22 *$ \\
\hline & Overall Liking & & & & & & & 1.00 & $0.14^{*}$ & $-0.20 *$ \\
\hline & ${ }^{\circ}$ Brix & & & & & & & & 1.00 & $-0.29 *$ \\
\hline
\end{tabular}

${ }^{\mathrm{z}}$ Asterisks that follow a column indicate statistical significance of pairwise correlation $(P<0.05)$.

Strongly correlated attributes $(R>0.60)$ are highlighted in bold text, whereas minus signs indicate negative correlations.

\section{Literature Cited}

Baldwin, E.A. 2002. Fruit flavor, volatile metabolism and consumer perceptions, p. 89-106. In: M. Knee (ed.). Fruit quality and its biological basis. CRC Press, Boca Raton, FL.

Brovelli, E.A., J.K. Brecht, W.B. Sherman, and C.A. Sims. 1995. Quality profile of fresh market melting and non-melting peach fruit. Proc. Fla. State Hort. Soc. 108:309-311.

Brovelli, E.A., J.K. Brecht, W.B. Sherman, C.A Sims, and J.M. Harrison. 1999. Sensory and compositional attributes of melting- and nonmelting-flesh peaches for the fresh market. J. Sci. Food Agr. 79:707-712.

Bruhn, C.M., N. Feldman, C. Garlitz, J. Harwood, E. Ivans, M. Marshall, A. Riley, D. Thurber, and E. Williamson. 1991. Consumer perceptions of quality: Apricots, cantaloupes, peaches, pears, strawberries, and tomatoes. J. Food Qual. 14:187-195.

Bruhn, C.M. 1995. Consumer and retailer satisfaction with the quality and size of California peaches and nectarines. J. Food Qual. 18:241256.

Colaric, M., R. Veberic, F. Stampar, and M. Hudina. 2005. Evaluation of peach and nectarine fruit quality and correlations between sensory and chemical attributes. J. Sci. Food Agr. 85:2611-2616.

Colquhoun, T.A., L.A. Levin, H.R. Moskowitz, V.M. Whitaker, D.G. Clark, and K.M. Folta. 2012. Framing the perfect strawberry: An exercise in consumer-assisted selection of fruit crops. J. Berry Res. 2:45-61.

Crisosto, C.H. 2002. How do we increase peach consumption? Acta Hort. 592:601-605.

Crisosto, C.H. and G.M. Crisosto. 2005. Relationship between ripe soluble solids concentration (RSSC) and consumer acceptance of high and low acid melting flesh peach and nectarine (Prunus persica (L.) Batsch) cultivars. Postharvest Biol. Technol. 38:239-246.

Crisosto, C.H. 2006. Peach quality and postharvest technology. Acta Hort. 713:479-487.

Crisosto, C.H., G.M. Crisosto, G. Echeverria, and J. Puy. 2006. Segregation of peach and nectarine (Prunus persica (L.) Batsch) cultivars according to their organoleptic characteristics. Postharvest Biol. Technol. 39:10-18.

Delgado, C., G.M. Crisosto, H. Heymann, and C.H. Crisosto. 2013. Determining the primary drivers of liking to predict consumers' acceptance of fresh nectarines and peaches. J. Food Sci. 78 : S605-S614.

DellaVigna, S. 2009. Psychology and economics: Evidence from the field. J. Econ. Lit. 47:315372.

Diehl, D.C., N.L. Sloan, C.M. Bruhn, A.H. Simonne, J.K. Brecht, and E.J. Mitcham. 2013. Exploring produce industry attitudes: Relationships between postharvest handling, fruit flavor, and consumer purchasing. HortTechnology 23:642-650.

Do, J.Y., D.K. Salunkhe, and L.E. Olson. 1969. Isolation, identification and comparison of the volatiles of peach fruit as related to harvest maturity and artificial ripening. J. Food Sci. 34:618-621.

Fresh Trends. 2011. The packer. Vance Publishing, Lenexa, KS.

Fresh Trends. 2012. The packer. Vance Publishing, Lenexa, KS.

Gallardo, R.K., D. Nguyen, V. McCracken, C. Yue, J. Luby, and J.R. McFerson. 2012. An investigation of trait prioritization in rosaceous fruit breeding programs. HortScience 47:771-776.

Gil, M.I., F.A. Tomás-Barberán, B. Hess-Pierce, and A.A. Kader. 2002. Antioxidant capacities, phenolic compounds, carotenoids, and vitamin $\mathrm{C}$ contents of nectarine, peach, and plum cultivars from California. J. Agr. Food Chem. 50:4976-4982.

Gilbert, J.L., J.W. Olmstead, T.A. Colquhoun, L.A. Levin, D.G. Clark, and H.R. Moskowitz. 2014 Consumer-assisted selection of blueberry fruit quality traits. HortScience 49:864-873.

Grimm, K.A., H.M. Blanck, K.S. Scanlon, L.V. Moore, L.M. Grummer-Strawn, and J.L. Foltz. 2010. State-specific trends in fruit and vegetable consumption among adults: United States, 2000 2009. Morb. Mortal. Wkly. Rpt. 59:1125-1130.

Harrison, E.H., J.X. Chaparro, and L. Harrison. 2008. Sub-tropical peach market improvement project. Fla. Dept. Agr. Consumer Serv., Div. Mktg. Dev., Tallahassee, FL.

Jaeger, S.R., Z. Andani, I.N. Wakeling, and H.J.H. MacFie. 1998. Consumer preferences for fresh and aged apples: A cross-cultural comparison. Food Qual. Prefer. 9:355-366.

Kader, A.A., C.M. Heintz, and A. Chordas. 1982. Postharvest quality of fresh and canned clingstone peaches as influenced by genotypes and maturity at harvest. J. Amer. Soc. Hort. Sci. 107:947-951.

Kader, A. 1999. Fruit maturity, ripening, and quality relationships. Acta Hort. 485:203-208.

Kao, M-W.S., J.K. Brecht, J.G. Williamson, and D.J. Huber. 2012. Ripening development and quality of melting and non-melting flesh peach cultivars. HortScience 47:879-885.

Karakurt, Y., D.J. Huber, and W.B. Sherman. 2000. Development of off-flavour in non-melting flesh peach genotypes. J. Food Sci. Agr. 80:1841-1847.

Laurens, F. 1999. Review of the current apple breeding programmes in the world: Objectives for scion cultivar improvement. Acta Hort. 484:163-170.

Lea, M.A., C. Ibeh, C. desBordes, M. Vizzotto, L. Cisneros-Zevallos, D.H. Byrne, W.R. Okie, and M.P. Moyer. 2008. Inhibition of growth and induction of differentiation of colon cancer cells by peach and plum phenolic compounds. Anticancer Res. 28:2067-2076.

Lester, D.R., W.B. Sherman, and B.J. Atwell. 1996. Endopolygalacturonase and the melting flesh (M) locus in peach. J. Amer. Soc. Hort. Sci. 121:231-235.

Levin, L.A., K.M. Langer, D.G. Clark, T.A. Colquhoun, J.L. Callaway, and H.R. Moskowitz. 2012. Using mind genomics ${ }^{\circledR}$ to identify essential attributes of a flower product. HortScience 47:1658-1665.

Lurie, S. and C.H. Crisosto. 2005. Chilling injury in peach and nectarine. Postharvest Biol. Technol. 37:195-208.

Martínez-García, P.J., C.P. Peace, D.E. Parfitt, E.A. Ogundiwin, J. Fresnedo-Ramírez, A.M. Dandekar, T.M. Gradziel, and C.H. Crisosto. 2012. Influence of year and genetic factors on chilling injury susceptibility in peach (Prunus persica (L.) Batsch). Euphytica 185:267-280.

Meredith, F.I., J.A. Robertson, and R.J. Horvat. 1989. Changes in physical and chemical parameters associated with quality and postharvest ripening of Harvester peaches. J. Agr. Food Chem. 37:1210-1214.

Morgan, K. and M. Olmstead. 2013. A diversification strategy for perennial crops in Florida. HortTechnology 23:482-489.

Moskowitz, H.R., A. Gofman, J. Beckley, and H. Ashman. 2006. Founding a new science: Mind genomics. J. Sens. Stud. 21:266-307. 
Moskowitz, H.R. and A. Gofman. 2007. Selling blue elephants. Prentice Hall, Upper Saddle River, NJ.

Moskowitz, H.R. 2012. 'Mind genomics': The experimental, inductive science of the ordinary, and its application to aspects of food and feeding. Physiol. Behav. 107:606-613.

Noratto, G., W. Porter, D. Byrne, and L. CisnerosZevallos. 2009. Identifying peach and plum polyphenols with chemopreventive potential against estrogen-independent breast cancer cells. J. Agr. Food Chem. 57:5219-5226.

Olienyk, P., A.R. Gonzalez, A. Mauromoustakos, W.K. Patterson, C.R. Rom, and J. Clark. 1997. Nitrogen fertilization affects quality of peach puree. HortScience 32:284-287.

Parker, D.D., D. Zilberman, and K.S. Moulton. 1991. How quality relates to price in California fresh peaches. Calif. Agr. 45:14-16.

Plackett, R.L. and J.P. Burman. 1946. The design of optimum multifactorial experiments. Biometrika 33:305-325.

Predieri, S., P. Ragazzini, and R. Rondelli. 2006. Sensory evaluation and peach fruit quality. Acta Hort. 713:429-434.

Price, J. and J. Riis. 2012. Behavioral Economics and the Psychology of Fruit and Vegetable Consumption: A Scientific Overview, 2012. 22 June 2015. <http://www.pbhfoundation.org/ pdfs/about/res/pbh_res/PBH_2012_LitReview. pdf $>$.

Redelmeier, D.A. and V.M. Dickinson. 2011. Determining whether a patient is feeling better: Pitfalls from the science of human perception. J. Gen. Intern. Med. 26:900-906.
Reig, G., I. Iglesias, F. Gatius, and S. Alegre. 2013. Antioxidant capacity, quality, and anthocyanin and nutrient contents of several peach cultivars [Prunus persica (L.) Batsch] grown in Spain. J. Agr. Food Chem. 61:6344-6357.

Robertson, J.A., F.I. Meredith, and R. Scorza. 1989. Physical, chemical and sensory evaluation of high and low quality peaches. Acta Hort. 254:155-160.

Rouse, R.E. and W.B. Sherman. 2002. Peaches for subtropical south Florida. J. Amer. Pomol. Soc. 56:206-207.

Rouse, R.E., W.B. Sherman, and P.M. Lyrene. 2004. UFSun. Peach. J. Amer. Pomol. Soc. 58:108-110

Santos, C.M.d., C.M.P. d. Abreu, J.M. Freire, and A. D. Corrêa. 2013. Atividade antioxidante de frutos de quatro cultivares de pessegueiro. Revista Brasileira de Fruticultura 35:339-344.

Schwieterman, M.L., T.A. Colquhoun, E.A. Jaworski, L.M. Bartoshuk, J.L. Gilbert, D.M. Tieman, A.Z. Odabasi, H.R. Moskowitz, K.M. Folta, H.J. Klee, C.A. Sims, V.M. Whitaker, and D.G. Clark. 2014. Strawberry flavor: Diverse chemical compositions, a seasonal influence, and effects on sensory perception. PLoS One 9:e88446.

Sherman, W.B., P.M. Lyrene, and R.H. Sharpe. 1996. Low-chill peach and nectarine breeding at the University of Florida. Proc. Fla. State Hort. Soc. 109:222-223.

Sherman, W.B. and P.M. Lyrene. 2003. Low chill breeding of deciduous fruits at the University of Florida. Acta Hort. 622:599-605.

Williamson, J.G. and S.A. Sargent. 1999. Postharvest characteristic and consumer acceptance of non-melting peaches. Proc. Fla. State Hort. Soc. 112:241-242.

Yue, C., R.K. Gallardo, J. Luby, A. Rihn, J.R. McFerson, V. McCracken, D. Bedford, S. Brown, K. Evans, C. Weebadde, A. Sebolt, and A.F. Iezzoni. 2013. An investigation of U.S. apple producers' trait prioritization: Evidence from audience surveys. HortScience 48:1378-1384.

Yue, C., R.K. Gallardo, J. Luby, A. Rihn, J.R. McFerson, V. McCracken, V.M. Whitaker, C. E. Finn, J.F. Hancock, C. Weebadde, A. Sebolt, and A. Iezzoni. 2014. An evaluation of U.S. strawberry producers trait prioritization: Evidence from audience surveys. HortScience 49:188-193.

United States Department of Health and Human Services. 2009. Code of Federal Regulations, Title 45, Part 46. 13 June 2014. <http://www. hhs.gov/ohrp/humansubjects/guidance/ 45cfr46.html\#46.101>.

United States Department of Agriculture. 2012. Census of Agriculture. 14 June 2015. <http:// agcensus.usda.gov/Publications/2012/Full_ Report/Volume_1,_Chapter_1_State_Level/ Florida/st12_1_039_040.pdf $>$.

United States Department of Agriculture. 2014. Fruit and Tree Nut Yearbook Spreadsheet Files. Per Capita Consumption of Selected Noncitrus Fruit, 1980/81 to Date. 22 June 2015. <http://usda.mannlib.cornell.edu/usda/ ers/89022/Table-G41.x1sx>.

Van der Heyden, C.R., P. Holford, and G.D. Richards. 1997. A new source of peach germplasm containing semi-freestone nonmelting flesh types. HortScience 32:288-289. 